\title{
O NOVO REALISMO ITALIANO: DE PASOLINI A SAVIANO
}

\author{
Giuliana Benvenuti
}

(Universidade de Bolonha)

Per Pasolini l'arte era un mezzo di comunicazione morale e politica, lo stile era un strumento, a volte provvisorio e semilavorato, per trasmettere un messaggio e dialogare con i contemporanei.

Alfonso Berardinelli

Já há algum tempo vem se desenvolvendo na Itália um debate sobre o "retorno ao real" por alguns escritores, porta-vozes da "fome de realidade" que caracterizaria a literatura não somente italiana nos últimos quinze ou vinte anos.

No contexto italiano, o debate seria devido de modo particularà reação de jovens escritores às diversas formas de pós-modernismo - sob a luz da última produção de Italo Calvino (Se um viajante numa noite de inverno e Palomar) e dos romances de Umberto Eco (a partir de $O$ nome da rosa) -, formas estas identificadas pela atitude irônica, descompromissada, metanarrativa, autorreferencial, contra a qual uma nova geração de autores, ou parte dela, se pronuncia.

O recente debate crítico sobre o "novo realismo" diz respeito à geração dos escritores entre 30 e 40 anos que recusa o pós-modernismo. O quadro, entretanto, é bem mais dinâmico. É preciso lembrar que: nem mesmo 
na Itália é possível nomear tudo o que foi escrito a partir da segunda metade dos anos 60 como pós-moderno; a tradição realista e a modernista mantiveram vitalidade; os últimos 15 anos foram marcados por um pósmoderno persistente (DONNARUMMA, 2008, p. 30).

Contudo, o dado novo é que hoje um realismo normatizado, híbrido e sem escândalos, prontoa seguirum rumo romanesco, intimista ou até mesmo fantástico, obtém grande sucesso comercial. Um realismo feito de romances que narram histórias criminais em formas tradicionais, recorrendo aos gêneros literários codificados, o policial e o romance de mistério (Giancarlo De Cataldo, Girolamo De Michele, Gianrico Carofiglio etc.).

Portanto, ao lado de autores que partindo de Calvino, como Antonio Tabucchi e Daniele Del Giudice, se endereçaram para uma narrativa de consumo que recuperou os esquemas da literatura de gênero, escritores que reinterpretam em modos originais os ditames do pós-modernismo como Sergio Siti e Nicola Lagioia - convivem escritores que abandonam os esquemas dos gêneros e se reportam a autores de difícil classificação, como Pasolini, praticando novas formas de escrita.

Entre os escritores de maior interesse está Roberto Saviano, em particular seu livro de estreia, Gomorra. Viagem no império econômico e no sonho de domínio da camorra (2006). Gomorra nasce de uma obsessão cívica: denunciar o funcionamento do "Sistema". Sistema é o nome com o qual se define a camorra (a máfia napolitana).

Saviano leva os leitores a refletir sobre o núcleo criminal do capital, interroga as dinâmicas do poder, do mercado e do consumo a partir da análise do sistema de poder camorrista. Aquilo que ocorre em um território circunscrito, a cidade de Nápoles e seus arredores, é posto em relação com a economia e com as trocas globais.

Saviano descreve, na primeira página, o porto de Nápoles:

“Tudo o que existe passa por aqui. Aqui, o porto de Nápoles. Não existe manufatura, tecido, peça de plástico, brinquedo, martelo, sapato, chave de fenda, porca, videogame, casaco, calça, furadeira, relógio que não passe pelo porto. $\mathrm{O}$ porto de Nápoles é uma ferida. Grande. Ponto final das viagens intermináveis das mercadorias. [...]. O porto de Nápoles é um buraco no mapa-múndi de onde sai o que se produz na China, no Extremo Oriente, como os jornalistas ainda se divertem em defini-lo [...]. Tudo o que se produz na China é despejado aqui. Como um baldinho cheio d'água que, quando derramado dentro de um buraco de areia, o alarga ainda mais e o faz crescer também em profundidade. Só o porto de Nápoles movimenta $20 \%$ do valor das importações têxteis da China, mas mais de $70 \%$ da quantidade de produtos também passa por aqui. É uma coisa complicada de entender, mas as mercadorias possuem magias raras: conseguem ser não sendo; chegar não chegando; ser caras mesmo sendo ordinárias; ser de pouco valor para o fisco mesmo sendo preciosas [...].” (SAVIANO, 2006, p. 12) 
"O porto fica afastado da cidade. Um apêndice infectado que nunca degenerou em peritonite, sempre conservado no abdomen da costa." (SAVIANO, 2006, p. 16)

A viagem no império econômico da camorra revela as interconexões entre a economia legal e a ilegal e reflete sobre a natureza das relações entre lugares de produção e de troca, de mercadorias e de corpos. O elemento da corporeidade, exibida também em seus aspectos crus e cruéis, é central em Gomorra. Saviano não hesita diante da descrição da brutalidade e da violência e nem poderia fazê-lo já que o objeto da sua análise é o crime organizado, mas veremos como nisso reproduz, criticando-os, os modos e motivos da cinematografia sobre a máfia e da literatura e do cinema pulp, de violência.

Gomorra é também um livro que conta ao mundo as transformações locais da cultura camorrista, mostrando as contradições que a globalização introduz nesse universo cultural. Age sobre a percepção da Itália em nível internacional, reelaborando e, em certa medida, desmentindo uma série de estereótipos ligados à internacionalização da máfia e da camorra, celebrizados por uma ampla cinematografia (de Coppola a Tarantino). A escritura de Saviano é sempre militante do testemunho, do repórter, do analista político-cultural (TRICOMI, 2010, p. 193). A literatura se volta para um projeto de modificação do real que tem como componente essencial a instância cognitiva, de denúncia, de escândalo. Sob esse aspecto, Saviano se reporta a Pasolini e o faz nas páginas dedicadas ao cimento armado, ao "petróleo do sul", à construção civil, principal motor da economia camorrista, da economia do Mezzogiorno inteiro e, no final das contas, da Itália (país no qual a especulação na construção civil teve, em diferentes fases, um papel essencial no desenvolvimento econômico).

\section{Leiamos esta página de Saviano:}

\footnotetext{
"Eu sei e tenho provas. Eu sei de onde se originam as riquezas e de onde tiram seu fedor. Fedor de afirmação e vitória. Eu sei como transpira o lucro. Eu sei. E a verdade da palavra não condena ninguém porque tudo devora e de tudo faz prova. E não deve arrastar contraprovas nem instruir processos. Observa, avalia, olha, ouve. Sabe. Não condena ninguém à cadeia e as testemunhas não voltam atrás. Ninguém se arrepende. Eu sei e tenho provas. Eu sei onde os manuais de economia dissipam, transformando seus fractais em matéria, coisas, ferro, tempo e contratos. Eu sei. E as minhas provas também sabem. As provas não estão escondidas em nenhum pen-drive enterrado num buraco debaixo da terra. Não tenho vídeos comprometedores em garagens escondidas em locais inacessíveis na montanha. Não possuo documentos xerocados dos serviços secretos. As provas não são confrontáveis porque soa parciais, filmadas pelo olhar, contadas com palavras e temperadas com emoções forjadas a ferro e fogo. Eu vejo, deduzo, olho, falo e, assim, testemunho: palavra feia que ainda
} 
pode valer quando revela 'é mentira' no ouvido de quem ouve as cantilenas das rimas paralelas dos mecanismos de poder. A verdade é parcial e, no fundo, se fosse reduzível a uma fórmula objetiva seria química. Eu sei e tenho provas. E, então, conto essas verdades" (SAVIANO, 2006, p. 234)

Antes de comentar oartigo de Pasolini do qual partiu Saviano, notemos brevemente que Saviano reivindica uma componente essencial da própria escritura:otestemunho. Oqueéafirmadoedenunciadoem Gomorra recebe a confirmação pelo amplo uso de documentos: atos de instrução, verbais de discussões, papéis da polícia, entrevistas e documentos públicos. Não papéis secretos ou verdades ocultas (que são abundantes nos romances pós-modernos inspirados nas teorias da conspiração). A confirmação é também dada pelas "íris", ou seja, pela visão direta, pelas palavras, pelas narrativas e pelas emoções. Nessa posição de testemunha que imerge, ou melhor, que nasceu no ambiente que narra, encontramos um elemento de aproximação a Pasolini "etnógrafo"' (a definição é de FORTINI, 1993, p. 35) que imergiu na realidade da periferia para depois contá-la em Ragazzi di vita, Accatone etc. Mais do que "observador participante", como talvez pudéssemos considerar Pasolini, Saviano é parte do território e da cultura que narra: éa "intimidade com o território" o que o torna testemunha digno de fé (BENEDETTI, 2008). Porém, mais do que este aspecto etnográfico, é a vontade de colocar a literatura a serviço da verdade, tornando-a híbrida e espúria, o que aproxima Saviano de Pasolini. É, portanto, ao Pasolini dos Escritos corsários que o autor de Gomorra se reporta, o Pasolini que escreve o artigo publicado no jornal Corriere della Sera em 14 de novembro de 1974, com o título “O que é este golpe?” (depois em Escritos corsários com o título "O romance dos massacres"):

"Eu sei.

Eu sei os nomes daquilo que é chamado "golpe' (e que na realidade é uma série de 'golpes' instituída como sistema de proteção ao poder).

Eu sei os nomes dos responsáveis pelo massacre de Milão de 12 de dezembro de 1969.

Eu sei os nomes dos responsáveis pelos massacres de Brescia e de Bolonha dos primeiros meses de 1974 .

Eu sei o nome da "cúpula" que manobrou, então, tanto os velhos fascistas idealizadores do "golpe" como os neofascistas autores materiais dos primeiros

${ }^{1}$ Il Pasolini che «si immerge» nella vita delle borgate è sato definito da Franco Fortini un «etnografo» che si aggira con il note book tra i giovani borgatari, evidenziando una delle contraddizioni che la pratica etnografica novecentesca ha posto in rilievo entro la dialettica di partecipazione e distanza di ogni lavoro sul campo, è il Pasolini che si pone seriamente e drammaticamente il problema di come «restituire» nella scrittura quell'esperienza. 
massacres e enfim, os "desconhecidos" autores materiais dos massacres mais recentes.

Eu sei os nomes que administraram as duas diferentes, ou melhor, opostas, fases da tensão: uma primeira fase anticomunista (Milão, 1969) e uma segunda fase antifascista (Brescia e Bolonha, 1974).

Eu sei os nomes do grupo de poderosos que, com a ajuda da CIA (e em segunda ordem, dos coronéis gregos da máfia), criaram primeiramente (aliás, em uma miserável falência) uma cruzada anticomunista para abafar 68 e, em seguida, sempre com a ajuda da CIA, reconstruíram uma virgindade antifascista para abafar o desastre do 'referendum'.

Eu sei os nomes daqueles que, entre uma missa e outra, deram as ordens e asseguraram a proteção política para os velhos generais (para se manter em pé, como reserva, a organização de um golpe de estado potencial), a jovens neofascistas, ou melhor, neonazistas (para criar concretamente a tensão anticomunista) e finalmente criminais comuns, até este momento e talvez para sempre, sem nomes (para criar a tensão seguinte antifascista). [...]

Eu sei todos esses nomes e sei todos os fatos (atentados às instituições e massacres) dos quais são culpados.

Eu sei. Mas não tenho provas. Não tenho sequer indícios.

Sei por que sou um intelectual, um escritor, que procura acompanhar tudo o que acontece, de conhecer tudo o que se escreve a respeito, de imaginar tudo o que não se sabe ou que é calado; que relaciona fatos mesmo distantes, que junta os pedaços desorganizados e fragmentários de um inteiro e coerente quadro político, que restabelece a lógica onde parece reinar a arbitrariedade, a loucura e o mistério.

Tudo isso faz parte da minha profissão e do instinto da minha profissão. [...] Acredito ainda que muitos outros intelectuais e romancistas saibam o que eu sei enquanto intelectuais e romancistas. Porque a reconstrução da Itália depois de 68 não é tão difícil assim." (PASOLINI, 1999).

Pasolini prossegue revindicando a necessidade de oposição ao poder por parte do intelectual. Um intelectual, porém - e Pasolini é plenamente consciente disso -, que já está, nos anos 6o, às margens, levado a intervir sobre questões morais e ideológicas, mas em formas convencionais que neutralizam o poder crítico, na verdade, mantido à distância das provas de verdades terríveis dos anos dos massacres na Itália. O terreno sobre o qual Saviano se move não é muito diferente daquele da marginalidade do intelectual e do escritor, no entanto, afirma ter as provas, provas deduzidas de atos públicos (ignorados, porém, pelo grande público que lê Gomorra) e provas testemunhais, dada a sua intimidade com o território.

Aquilo que Saviano conta é, portanto, real mesmo quando recorre à ficção literária, é verdadeiro mesmo quando não o é literalmente. Não é importante que o eu narrador seja sempre testemunha ocular dos fatos narrados ou que recolha outros testemunhos. A contaminação entre ficção e não-ficção é colocada a serviço da reconstrução das lógicas do poder camorrista, a literatura persegue a busca pela realidade, como 
frequentemente acontece nos assim chamados "non-fiction novel" que utilizam sempre os instrumentos literários e a invenção para reconstruir cenários, preencher lacunas, imaginar pensamentos e explicar comportamentos. A evocação de Pasolini nesta zona central, de todos os pontos de vista, de Gomorra é um ato de acusação contra a literatura e a intelligentsia italianas dos últimos trinta anos, que abandonaram qualquer ideia de literatura e cultura como bens públicos, pertencentes a uma comunidade.

O próprio Pasolini, sabemos, já observava dolorosamente como a literatura nos anos 70 havia perdido sua relevância cívica. Também por essa razão Pasolini se torna "corsário", para denunciar o apocalipse cultural, o fim do humanismo e o advento da época do triunfo do consumo. Pasolini nunca perdeu a confiança na palavra, uma espécie de fé incondicional na palavra, profundamente convencido de dever proclamar verdades que somente a literatura e quem a exerce podem proclamar e devem proclamála. Essa confiança na palavra foi a força herdada por Saviano e junto a ela, em uníssono com ela, uma prática espúria da literatura, disposta a lançar mão de qualquer meio para obter um auditório, um público de leitores não mais garantido pela centralidade da formação humanista na educação das elites.

Pasolini, aliás, como hoje Saviano, não hesitou em renunciar à comunidade de literatos, cada vez mais hipotética e espectral, para se tornar sempre mais um formador de opinião, procurando desfrutar o capital simbólico residual doado ao poeta. Operação por ele mesmo percebida como destinada ao fracasso e que, apesar disso, continua a executá-la, como último gesto de dissidência política.

\footnotetext{
Assim, as últimas obras de Pasolini não são simplesmente apocalípticas, isto é, obras de um intelectual que acredita reconhecer na degradação social ao seu redor os indícios do fim iminente da civilização. Cada uma delas parece também constituir um testamento específico. Testamento este que o autor, antes de ser o primeiro a declarar sua própria tentativa falimentar, gostaria de deixá-la a determinados interlocutores que se revelam porém inalcançáveis ou desinteressados em receber suas palavras de despedida ou incapazes de entendê-las. Trata-se portanto de uma desesperada e vã procura por um público, conduzida nos anos 70 por Pasolini, visível e legitimamente convencido de não ser ouvido. (TRICOMI, 2010, p. 176)
}

O problema é reproposto em novos termos para Saviano, que procurou e encontrou um público próprio. E o encontrou também porque soube intersectar originalmente sua escritura com o imaginário sempre mais globalizado do nosso presente, em particular desfrutando o sucesso do cinema e da literatura que contam histórias criminais. Saviano 
introduziu um desvio em relação a esse cinema e literatura, colocando, no centro da narração, seu testemunho pessoal, sem que tivesse renunciado à ficção, misturando os dois planos para dar vida a um organismo narrativo original.

Como escreve Casadei, existe um "efeito de irrealidade presente em qualquer âmbito interpretativo da história, parte da hipótese de uma continuidade entre tempos diferentes". "Efeito de irrealidade" que também diz respeito à narração da crônica, determinado pela invasividade da "cultura visual" (CASADEI, 2007, p. 22), pelo fato de que estamos imersos em um fluxo contínuo de informações e imagens, pela revolução antropológica determinada pela interconexão global graças aos novos meios de comunicação, pela espetacularização da existência, pelo fato de que nenhuma experiência nossa possa se dar sem estabelecer relações com o imaginário produzido pela mídia muito mais invasiva que a literatura. Estamos, portanto, imersos numa rede na qual é sempre mais difícil separar o real da ficção e principalmente no que diz respeito à crônica: o jornalismo televisivo, por exemplo, mistura informação documental e reconstruções "ficcionais", assim como os reality show pedem a pessoas "comuns" que interpretem, representem a si mesmas, em um estranho curto-circuito entre vida e ficção. Pensemos nas transmissões televisivas que nos prometem em continuação revelar a verdade oculta sobre o passado recente dos massacres italianos e constroem, tendo como base alguns indícios e pouquíssimas provas, hipóteses explicativas muito parecidas com as tramas de um romance policial sobre as teorias da conspiração, ou seja, sobre o gênero de maior sucesso do pós-modernismo. Podemos falar de uma espécie de forma degradada e espetacularizada da denúncia do poder feita pelo intelectual. Forma esta hoje já transformada em um formato convencional televisivo, previsível e bem pouco escandaloso. A partir dele, tudo pode ser dito, mesmo verdades atrozes, mas usando formas comunicativas que não são mais capazes de envolver o leitor em autêntica indignação.

$\mathrm{O}$ fenômeno é semelhante àquele denunciado pelo jovem escritor, estudioso da mídia, Antonio Scurati, que mostrou como a guerra, experiência traumática por excelência, reduziu-se a uma parte do mundo do espetáculo, consumido quotidianamente, "com uma cerveja na mão" por espectadores comodamente instalados em seus sofás (SCURATI, 2006, p. 387). Como uma reação a esse estado de coisas, reapareceu nos escritores mais jovens uma tensão ética que vai de par com a renascente confiança na potencialidade cognitiva da literatura, principalmente do romance, capaz de se ancorar na realidade em novas formas, mesmo que sejam aquelas da busca por uma realidade permeada pela ficção. Terreno 
escorregadio, difícil de ser praticado, que Saviano consegue percorrer graças à força da própria posição de testemunha.

A escritura de Saviano se coloca entre o mais genérico "retorno à narração" e a manipulação das formas fechadas, mas de modo original, rompendo o pacto do gênero, ao qual o leitor contemporâneo novamente se habituou na Itália, depois que, a partir dos anos 8o, os gêneros literários foram restaurados. $\mathrm{O}$ rompimento com qualquer pacto de gênero libera a escritura de Saviano de vínculos incômodos (a matéria - o crime organizado - prestar-se-ia a ser narrada na forma do romance de mistério, como ocorre frequentemente) e contribui dando força a uma enunciação que possui caracteres testemunhais. Para fazê-lo, Saviano, seguindo os rastros de Pasolini, retoma uma escritura híbrida, não codificável. Esse desvio em relação à nova norma, que retorna às formas literárias codificadas, é fundamental, é o que permite à literatura se livrar das formas comunicativas às quais o leitor/espectador está habituado, retirando-o do torpor e o interpelando. É o que a literatura modernista havia procurado fazer quando, com diferentes recursos narrativos, impedia que o leitor se identificasse com enredos edificantes, asseguradores, burgueses e conformistas. Mas mesmo esses instrumentos se desgastaram.

Pasolini compartilhava com muitos escritores contemporâneos a capacidade de alternar, mas também de hibridizar, em um único texto, uma pluralidade de registros discursivos: o ensaísmo, não somente o de reflexão política, e a literatura trocavam de papéis em continuação, justamente porque esses escritores eram, sobretudo, intelectuais preocupados em encontrar o melhor caminho para intervir no debate público (BERARDINELLI, 1990). Numa literatura como a italiana, órfã de uma sólida tradição romanesca, o ato de se curvar diante dos gêneros, iniciado nos anos 80 do século passado, não produziu, pelo menos na prosa, resultados relevantes. Recuperar a lição de autores capazes de construir formas textuais espúrias para melhor interpretar a história e o presente (Luciano Bianciardi, Domenico Rea, Nanni Balestrini, por exemplo) pode então querer dizer, para Saviano e talvez para outros escritores da sua geração, tentar restituir, a nossa literatura, um lastro social. Com esse objetivo, o leitor é envolvido em narrações que têm a intenção de modificar sua percepção do presente, ou do passado através do presente, para levá-lo à recusa, à negação de um alinhamento ao poder, à resistência, à ação, embora alguns dos autores que escolhem a história e a crônica como objeto narrativo proponham uma modalidade que definem como "performativa." (BENVENUTI, 2012).

A modalidade performativa aposta na dimensão afetiva e nela predominam as observações de tipo autobiográfico e autoetnográfico 
(como em Saviano), ou então de tonalidades épicas (Wu Ming, Genna, De Michele). O tecido evocativo e afetivo desses romances pede ao leitor cumplicidade e afinidade emotiva. A literatura deve se propor como narrativa capaz de dar vida a uma coletividade, refundando, através das práticas da narração, um discurso comum de pertencimento cultural, cívico e político. A narração, em suma, tenta um caminho para se inscrever novamente na práxis. A divergência que Calvino apontava entre a realidade e a escritura, a escritura que deveria ser ágil, rápida, versátil, elegante em oposição à realidade opaca, pesada, inamovível, o levara a desviar o olhar da massa grave e inerte do mundo real para não se tornar petrificado e o convencia a recorrer a triangulações e jogos de espelhos para fugir da Medusa. Tal divergência, portanto, é agora sentida como abordável em novas formas de intervenção literária: não mais pelo jogo das possibilidades infinitas, mas na chamada à responsabilidade da palavra, da sua capacidade de intervenção, na sua capacidade de modificar, e não só de desnudar, as relações de força da sociedade.

Isto significa que esses autores, mais do que confiar na capacidade reflexiva e construtiva da "literatura", confiam na sua capacidade empática e afetiva, produzindo um discurso literário de característica claramente performativa. Em alguns casos, há a conotação de uma vontade política determinada e sustentada pela persuasão de que, se por um lado, da sociedade dos simulacros, não se sai com as armas do imaginário, por outro, o imaginário contribui para a criação da realidade. Trabalhando sobre si mesma nessa direção, a literatura se subtrai à imagem do assim chamado pós-modernismo 'eufórico', sem que negue algumas aquisições formais do pós-modernismo: contaminação entre os gêneros, sobreposição dos planos temporais, proliferação das vozes e dos pontos de vista e, sobretudo, abolição da distinção entre literatura 'alta' e literatura 'popular'.

Se considerarmos que o pós-moderno fez da abolição da distinção entre os gêneros e, mais ainda, da contaminação da literatura 'alta' e 'popular' uma prática corrente, podemos afirmar que há uma continuidade entre o pós-moderno e certa literatura do novo século. Isso não deve levar, entretanto, à subestimação das descontinuidades explicitamente reivindicadas por alguns autores: descontinuidades relevantes, entre as quais, em primeiro lugar, a "participação emotiva" e a "tensão ética" contrapostas à distância irônica. Se considerarmos a renovação formal: “objetos narrativos não identificados" (Wu Ming, 2009), portanto fora dos esquemas de gênero ou desmontando-os internamente, mas, apesar disso, na maioria dos casos, com coerência narrativa. Essa garantia não advém, entretanto, de hipóteses combinatórias, mas sim de um retorno à narração. 
O abandono do paradigma moderno da novidade como valor estético é dirimente, mas ao mesmo tempo bastante problemático. Difícil o ponto de encontro entre renovação e vontade de alcançar um público amplo, de interagir com um imaginário "colonizado" por ícones propostos pela mídia, mais fortes e invasivos. Difícil, em suma, dar vida a uma escritura que seja popular sem ser padronizada, a romances que sejam potencialmente best-sellers sem perder a possibilidade de "divergência" em relação aos modelos dominantes do consumo. A convicção de muitos escritores "performativos" - e primeiro entre eles Saviano, desde a estreia na rede (Saviano era blogger antes de se tornar romancista) (WEBER 2007), consciente de que a mera exibição de documentos deixaria seus leitores indiferentes - é de que a narração seja eficaz no terreno das novas formas de comunicação. Não, porém, exibindo simplesmente provas das mentiras das narrações dominantes, mas sim criando contranarrações capazes de envolver um público o mais amplo possível. Dessa convicção nasce Gomorra, no delicado ponto de intersecção entre prova documentária, ficção e autoficção romanescas.

Uma das coisas que mais impressiona em Gomorra é a interação entre o imaginário fílmico e as práticas dos camorristas. Há um capítulo dedicado ao cinema no qual se fala sobre como os boss se inspiram no cinema em seus comportamentos, no modo de vestir, no modo de apresentar seus seguranças, resumindo, como usam o cinema como valor simbólico, tendo como certo a potência e a penetração no imaginário de alguns grandes filmes de máfia. O poder do boss se manifesta desse modo, por exemplo, na construção de uma mansão idêntica àquela do protagonista de Scarface. Mas ainda tem mais: há o caso de dois jovens aspirantes a camorristas que levam a sério o exemplo do filme de Tarantino e pensam poder desconsiderar a rígida organização do Sistema, poder se virar sozinhos, e por isso acabarão assassinados. Saviano, portanto, encena a intersecção entre a realidade e a ficção que ele próprio utiliza no seu livro como elemento fundador não só do imaginário, mas também das práticas: o imaginário cria realidade, além de ser por ela criado. E hoje de modo crescente e sem dúvida alguma incomparavelmente maior em relação ao passado. Gomorra, portanto, se configura como reflexão crítica e divergente diante daquilo que só poderia resumir com um slogan "a vida como realidade", mas ao mesmo tempo não se pode simplesmente "sair" da sociedade dos simulacros, do espetáculo. Gomorra torna evidente essa contradição. O escritor que pretender criticar a sociedade dos simulacros se dirige para o terreno da política dos afetos e a literatura se torna performativa: procura aproximar prova documental, tensão ética e envolvimento emotivo. Por essa razão, é possível dizer-se que Saviano não passa de um "herói de papel" (DAL LAGO, 2010), mas se 
pode e talvez se deva também reconhecer que é um escritor que procura dar vida a uma literatura divergente, usando as armas do inimigo. Não se sai da sociedade dos simulacros somente com as armas do imaginário, embora o imaginário contribua a criar a realidade.

Se é verdade que a realidade tem muita dificuldade em competir com a ficção, que o extratexto agoniza entre suas representações, parece possível então concluir que a oposição ao poder deva usar os mesmos instrumentos, deva fazer com que surjam textos de forte impacto afetivo, que envolvam emotivamente e entrem em concorrência nesse plano no mercado das mídias. A capacidade de envolver emocionalmente o público parece ser a maior preocupação dos políticos que tomam lições com os realiity shows e com os jornalistas os quais, frequentemente, para falar em complôs, acabam por construir tramas de thriller, criam ficções que envolvem os leitores e os espectadores através do impacto emotivo despertado pelas narrativas de sofrimentos individuais. Nessa mesma direção, não contrária, mas sim confluente àquela que estamos analisando, realidade e ficção se confundem: a crônica e a reconstrução histórica, para alcançarem audiência, necessitam de uma hábil armação dramática e, portanto, não se hesita em fazer uso de técnicas narrativas romanescas. É nesse plano de mobilização das emoções que hoje se desenrola a luta política quando estão esgotadas as fortes paixões políticas que a caracterizavam até pouco tempo atrás, polarizando-a e radicalizando-a.

Afirmar que hoje assistimos à completa despolitização das emoções, já que dificilmente as ideias políticas catalisam nossas paixões, não significa afirmar que não representem um instrumento de mobilização. Gomorra procura mobilizar o leitor, envolvê-lo, transtorná-lo e levá-lo à recusa.

Movendo-se sobre um terreno difícil, por alguns considerado ambíguo, não é de se surpreender que Saviano tenha sido acolhido entusiasticamente e, ao mesmo tempo, com duras críticas. Saviano oferece uma representação não heroica do crime organizado, procura 'deseroicizar' as figuras dos boss que o cinema representou como herói do mal. Explora o interesse do público, incluindo o público internacional, pela máfia, oferecendo uma visão divergente, não conformista. Gomorra oferece a representação do mal como um mundo degradado no qual triunfa o interesse econômico por si só, no qual a exploração do trabalho, no limite da escravidão, não desperta nenhum entusiasmo ou fascínio. Não existe nada de fascinante nos heróis do mal, não existem as regras, no fundo compreensíveis e admissíveis, de um código de honra. O que existe é a realidade crua e impiedosa da exploração. O único herói, como mostra Dal Lago, na sua crítica feroz a Saviano, é o autor, aquele que teve a coragem de dizer a verdade e por isso arrisca a vida. 
Desmistificar uma representação ambígua do mundo do mal (o mal absoluto possui seu fascínio, explorado pelo cinema e pela literatura de gênero) tem como contrapartida heroicizar quem a ele se opõe, neste caso, o herói e mártir Saviano. Oferecer-se como modelo de comportamento, como intelectual do escândalo e da denúncia é inevitável para quem desafia o poder, como Pasolini e Saviano. A compreensão dessa exemplaridade encarnada pelo escritor é frequentemente outra. A acusação de criar uma auto-mitobiografia, de se arvorar em juiz absoluto, foi atribuída a Pasolini e hoje é atribuída a Saviano. Mas o risco maior para esses autores, o que no mundo da globalização é ainda mais agudo, é o de, ao denunciar, fazer uso da mesma linguagem daqueles que são acusados. Na obra de Saviano, a hipérbole, a violência, o sangue são postos a serviço de objetivos opostos àqueles de quem leva o público a desfrutar da "literatura dos extremos": uma escritura que, respondendo ao vazio da realidade da sociedade do espetáculo, procura construir emoções fictícias sempre mais violentas e intensas, mas falsas. De quem oferece o espetáculo do mal e da violência a um público que, comodamente sentado no sofá em casa, não se expõe ao risco real, mas sim à emoção alimentada pelo consumo virtual de uma violência espetacularizada.

Saviano também responde à "fome de realidade" que é, entretanto, perpassada pela mediação literária. Portanto, é possível ter leituras opostas da sua obra: a primeira frisa o fato de que na Itália se renova a tradição de certa literatura cívica que volta a almejar o impacto social; a segunda insiste sobre a pouca qualidade literária da escritura de Saviano ao nivelar sua própria narração, rebaixando-a, recorrendo a hipérboles fáceis e aos clichês dos filmes de violência.

Do nosso ponto de vista - mesmo sendo inegável que Saviano escolheu (uma escolha consciente e vencedora no plano do sucesso de público) uma escrita fortemente comunicativa e emocionalmente envolvente, não desprezando efeitos retóricos "fáceis" -, é preciso ressaltar como positivo não somente o empenho cívico renovado, mas também a relativa novidade das soluções narrativas de Saviano que, seguindo as pegadas de Pasolini, contamina a literatura. Desta vez, ele a contamina com algo que Pasolini provavelmente teria desprezado: o imaginário mediático. Mas o ponto de maior novidade e valor, e de maior proximidade com Pasolini, é aquele que diz respeito ao plano da enunciação. De onde e quem fala em Gomorra? Quem é o eu narrador que, em poucas páginas, passa de um gênero a outro com absoluta desenvoltura? Quem é que diz "eu" em Gomorra? É sempre o autor e somente ele? Esse eu narrador recolhe também experiências de outros e se faz porta-voz. Isso é facilmente compreensível lendo as reflexões desse eu nas cenas dos delitos. Diante de cadáveres com 
as vísceras expostas, encharcados de sangue etc. Convido vocês a relerem aquelas páginas. Quem é esse eu que é sempre o primeiro a chegar aos locais dos homicídios e está sempre entre os primeiríssimos a ver o corpo? A ficção entrelaçada à realidade é constitutiva da própria voz narrativa. Introduzir a ficção na reportagem não significa inventar eventos, ou pelo menos não somente. Significa operar com técnicas literárias de modo que esses eventos possam ser relacionados um ao outro, dispostos no mesmo contexto, comunicados ao leitor. O elemento funcional se presta a derrubar as fronteiras entre ficção e não-ficção o que serve, por sua vez, a descrever a realidade de modo mais potente.

Tradução: Maria Betânia Amoroso

\section{REFERÊNCIAS BIBLIOGRÁFICAS}

BENEDETTI, Carla. Le quattro forze di Gomorra, http://www.ilprimoamore.com/old/ testo_922.html.

BENVENUTI, Giuliana. Il romanzo neostorico in Italia: storia, memoria, narrazione. Roma: Carocci, 2012.

BERARDINELLI, Alfonso. Tra il libro e la vita: situazioni della letteratura contemporanea. Torino: Bollati Boringhieri, 1990.

CALVINO, Italo. Se una notte d'inverno un viaggiatore. In: Romanzi e racconti, ed. dir. da C. Milanini, a cura di M. Barenghi, B. Falcetto. Milano: Mondadori, 1997.

. Palomar. In: Romanzi e racconti, ed. dir. da C. Milanini, a cura di M. Barenghi, B. Falcetto. Milano: Mondadori, 1997.

CASADEI, Alberto. Stile e tradizione nel romanzo italiano contemporaneo. Bologna: il Mulino, 2007.

DAL LAGO, Alessandro. Eroi di carta: il caso Gomorra e altre epopee. Roma: Manifestolibri, 2010 .

DONNARUMMA Raffaele. Nuovi realismi e persistenze postmoderne: narratori italiani di oggi. Allegoria, n. 57, pp. 26-56.

ECO, Umberto. Il nome della rosa. Milano: Bompiani, 2012.

FORTINI, Franco. Attraverso Pasolini. Torino: Einaudi, 1993.

PASOLINI, Pier Paolo, Scritti Corsari. In: Saggi sulla politica e sulla società, a cura di W. Siti, S. De Laude. Milano: Mondadori, 1999. 
248 - Remate de Males 34.1

SAVIANO, Roberto, Gomorra: viaggio nell'impero economico della camorra. Milano: Mondadori, 2006.

SCURATI, Antonio. Il rumore sordo della battaglia. Milano: Bompiani, 2006.

TRICOMI, Antonio. La Repubblica delle Lettere: generazioni, scrittori, società nell'Italia contemporanea. Macerata: Quodlibet, 2010.

WEBER, Luigi, Serpico, Scarface e Papillon: su Gomorra di Roberto Saviano. In: Studi Culturali, Bologna: il Mulino, 3, 2007.

MING. Wu. New Italian Epic: letteratura, sguardo obliquo, ritorno al futuro. Torino: Einaudi, 2009. 